\title{
Impacto do microclima sobre a fisiologia, pelame e produção de leite de vacas lactantes em diferentes estações do ano
}

\author{
Impact of microclimate on the physiology, hair coat and milk production of dairy cows at different \\ seasons
}

\section{Laize Vieira Santos ${ }^{1 *}$, Cinara da Cunha Siqueira Carvalho², José Reinaldo Mendes Ruas ${ }^{3}$, Thamara Amaral Diniz² ${ }^{2}$ Edilane Aparecida da Silva ${ }^{3}$ \& Sóstenes de Jesus Magalhães Moreira ${ }^{1}$}

\author{
${ }^{1}$ Universidade Estadual do Sudoeste da Bahia, latapetinga, BA, Brasil. * Autor para correspondência: santos.laize@yahoo.com.br. \\ 2 Universidade Estadual de Montes Claros, Montes Claros, MG, Brasil. \\ ${ }^{3}$ Empresa de Pesquisa Agropecuária de Minas Gerais, Belo Horizonte, MG, Brasil.
}

Submissão: 20/04/2017 | Aceite: 13/06/2018

\begin{abstract}
RESUMO
Objetivou-se com este trabalho avaliar o efeito do ambiente climático sobre as respostas fisiológicas, alterações no pelame e produção de leite de vacas F1 Holandês x Zebu, de diferentes bases maternas em duas estações do ano distintas. O trabalho foi conduzido na Fazenda Experimental da Empresa de Pesquisa Agropecuária de Minas Gerais, no município de Felixlândia, Minas Gerais. Foram avaliadas 50 vacas em lactação em duas épocas do ano (outono e primavera), com período de avaliação de 21 dias, com 25 animais avaliados em cada época, pertencentes a 5 grupos genéticos, sendo cada grupo composto por 5 animais. Foram feitas medições diárias da temperatura e umidade relativa do ar, com o uso de dataloggers de leitura contínua, em intervalos de 10 minutos. Foram mensurados com auxílio de estetoscópio, termômetro clínico digital e termômetro de infravermelho digital portátil os seguintes parâmetros fisiológicos: frequência respiratória e cardíaca, temperatura de superfície corporal e temperatura retal. As medições foram realizadas antes e após as ordenhas pela manhã e à tarde, diariamente, no outono e na primavera. O delineamento utilizado foi 0 inteiramente casualizado em esquema fatorial $5 \times 2$ ( 5 grupos genéticos e 2 épocas do ano). As variáveis foram submetidas à análise de variância e, quando significativas pelo teste $\mathrm{F}$, tiveram as médias comparadas pelo teste de Tukey a $5 \%$ de probabilidade. Não houve variação para a maioria dos parâmetros fisiológicos estudados, entre os grupos genéticos, sendo estes mais elevados na época da primavera e no horário da tarde (média de 33,2 movimentos respiratórios por minuto, 79,4 batimentos cardíacos por minuto, temperatura de superfície corporal de $33,7^{\circ} \mathrm{C}$ e temperatura retal de $38,7^{\circ} \mathrm{C}$ ). As variáveis ambientais nas duas estações do ano não promoveram alterações nas respostas produtivas dos animais (temperatura do ar máxima de $40,1^{\circ} \mathrm{C}$ e $44,8^{\circ} \mathrm{C}$ e índice de temperatura de globo negro e umidade máximo de 95,4 e 96,0 no outono e primavera, respectivamente), indicando a adaptação e resistência dos animais F1 Holandês x Zebu.
\end{abstract}

PALAVRAS-CHAVE: adaptabilidade, ambiência, bovinos leiteiros.

\begin{abstract}
The objective of this study was to evaluate the effects of the climatic environment on the physiological responses, changes in the hair coat and milk production of F1 Holstein and Zebu cattle from different maternal bases in two different seasons of the year. The study was conducted at the Experimental Farm of the Agricultural Research Company of Minas Gerais, in municipality of Felixlândia - Minas Gerais. Fifty dairy cows were evaluated in two seasons of the year (autumn and spring) for 21 days, with 25 animals evaluated in each season, belonging to 5 genetic groups, each group being composed of 5 animals. Daily measurements of air temperature and relative humidity were made using continuous reading dataloggers, at 10-minute intervals. The following physiological parameters were measured using a stethoscope, digital clinical thermometer and portable digital infrared thermometer: respiratory and cardiac frequency, body surface temperature and rectal temperature. Measurements were performed before and after milking in the morning and afternoon, daily in both evaluated seasons. The design was completely randomized in factorial scheme $5 \times 2$ ( 5 genetic groups and 2 seasons of the year). The variables were submitted to analysis of variance and, when significant to the $\mathrm{F}$ test, the means were compared by Tukey's test at $5 \%$ of probability. There was no variation for most of the studied physiological parameters among the genetic groups, being higher during spring and in the afternoon (mean values: 33.2 breaths per minute, 79.4 heart
\end{abstract}


rate per minute, $33.7^{\circ} \mathrm{C}$ body surface temperature and $38.7^{\circ} \mathrm{C}$ rectal temperature). The environmental variables in the two seasons of the year caused no changes in the productive responses of the animals $\left(40.1{ }^{\circ} \mathrm{C}\right.$ and $44.8{ }^{\circ} \mathrm{C}$ maximum air temperature and 95.4 and 96.0 maximum globe temperature and humidity index during autumn and spring, respectively), indicating the adaptation and resistance of $\mathrm{F} 1$ Holstein and Zebu animals.

KEYWORDS: adaptability, ambience, dairy cattle.

\section{INTRODUÇÃO}

A produção de leite no Brasil começou de forma extrativista e atualmente possui posição de destaque no cenário econômico nacional, sendo um dos principais agronegócios brasileiros. O país é o quinto maior produtor de leite do mundo e cresce a uma taxa anual de $4 \%$, respondendo por $66 \%$ do volume total de leite produzido nos países que compõem o Mercosul (CARVALHO et al. 2016).

Contudo, a produção brasileira de leite, assim como em outras regiões tropicais, está diretamente ligada ao grupo de animais oriundos de cruzamentos direcionados que se adaptaram melhor às condições climáticas. Aproximadamente $64 \%$ do rebanho de bovinos do mundo são criados em regiões de clima quente. No entanto, verifica-se produtividade menor que em regiões temperadas, ocorrendo lentas taxas de aumento e baixa produtividade (AZEVEDO et al. 2005, SEJIAN et al. 2010).

O rebanho brasileiro é composto em sua maioria por vacas mestiças e a alternativa em se utilizar esses animais deve-se a várias razões, tais como: boa opção para o regime em pastejo, pois possuem uma maior rusticidade, o que as fazem suportar maiores variações no ambiente e nos sistemas de manejo; maior longevidade, além de apresentar menor custo de produção quando se compara a sistemas com uso de animais puros (VASCONCELLOS et al. 2003).

A utilização de fêmeas mestiças F1 para a produção leiteira deve ser considerada como uma alternativa viável, principalmente para obtenção de leite a baixo custo, salientando que o sistema permite maximizar a utilização do efeito da heterose e da complementaridade entre raças. Os cruzamentos realizados entre raças zebuínas e européias se destacam no Brasil devido à adaptabilidade que esses animais desenvolveram para continuar produzindo em locais onde as condições climáticas, sanitárias e econômicas são diferenciadas (RUAS et al. 2010).

A produção leiteira possui grande correlação com as condições ambientais em que os animais são mantidos e com a capacidade desses animais em manterem a sua temperatura corporal dentro de limites considerados normais, na sua faixa termoneutra, onde os mesmos não necessitam desviar os nutrientes destinados à produção para a manutenção da sua temperatura corporal (SILVA 2000). Dessa forma, para manter a temperatura dentro desses limites, os animais tendem a alterar a sua fisiologia, de maneira mais ou menos expressiva, na tentativa de se adequar ao ambiente e às condições climáticas onde vivem (BAÊTA \& SOUZA 2010).

Assim, objetivou-se com este trabalho avaliar o efeito do ambiente climático sobre as respostas fisiológicas, alterações no pelame e produção de leite de vacas F1 Holandês x Zebu, de diferentes bases maternas, em duas estações do ano distintas.

\section{MATERIAL E MÉTODOS}

O presente trabalho foi avaliado e aprovado pelo Comitê de Ética em Experimentação e Bem-estar Animal (CEEBA) da Universidade Estadual de Montes Claros, $n^{\circ}$ 083/2015.

O trabalho foi conduzido na Fazenda Experimental da Empresa de Pesquisa Agropecuária de Minas Gerais (EPAMIG), no município de Felixlândia, Minas Gerais. A área experimental está localizada a uma

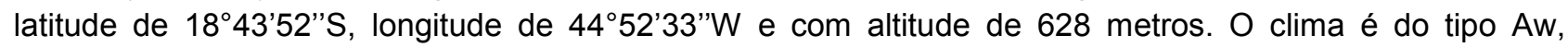
segundo a classificação de Köppen (tropical com estação seca). O índice pluviométrico anual é de 1118,9 $\mathrm{mm}$, com temperaturas médias anuais de $22,6^{\circ} \mathrm{C}$.

Foram avaliadas o total de 50 vacas em duas épocas do ano (outono e primavera), com período de avaliação de 21 dias em cada época. Os 25 animais avaliados por época pertenciam a 5 grupos genéticos diferentes: (50\%) Holandês x (50\%) Nelore, (50\%) Holandês x (50\%) Gir, (50\%) Holandês x (50\%) Guzerá, $(50 \%)$ Holandês $\times(50 \%)$ Zebu e $(50 \%)$ Holandês $\times(25 \%)$ Nelore $\times(25 \%)$ Gir, sendo cada grupo composto por 5 animais. Os grupos foram previamente separados de acordo com o peso, produção de leite e estádio de lactação, agrupando-se animais com características homogêneas. Os animais apresentavam peso médio de 555 quilos e produção de leite média diária 13,5 quilos.

Na primeira época (outono), os animais permaneceram em piquetes de Brachiaria decumbens, com 
área de 3,5; 3,6 e 5,8 hectares, havendo rodízio de pastos a cada 5 dias. Na segunda época (primavera), os animais permaneciam em piquetes de Brachiaria decumbens $\mathrm{cv}$. Xaraes e Tifton 85, com área de 1 hectare cada, havendo rodízio a cada 2 dias.

No período do outono, durante o dia, as vacas tiveram acesso ao pasto com suplementação no cocho de sal mineral e água à vontade e, entre o final da tarde e manhã do dia seguinte, recebiam cerca de 40 quilos de uma mistura de silagem de milho com cana-de-açúcar picada. Já na primavera, além do pasto, recebiam cerca de 35 quilos de silagem de milho, sal mineral e água à vontade.

A ordenha foi realizada pela manhã (7:00 h) e à tarde (14:00 h), com uso de ordenhadeira mecânica e bezerro ao pé, momento em que os animais recebiam ração farelada comercial, fornecida em função da produção individual de leite.

Foram feitas medições diárias da temperatura e umidade relativa do ar, com o uso de dataloggers de leitura contínua (modelo RHT 10, marca Instrutemp) instalados no brete de contenção dos animais, posicionados a uma altura de $1,70 \mathrm{~m}$ do piso e programados para coletar as variáveis climáticas a cada 10 minutos. Foram utilizados 2 dataloggers (um no interior do globo negro, para mensuração da temperatura de globo negro e outro fora do globo, para mensurar a temperatura de bulbo seco e temperatura de ponto de orvalho). Para caracterizar as faixas de conforto térmico e de posse dos dados coletados, foi calculado 0 índice de temperatura de globo e umidade (ITGU) proposto por BUFFINGTON et al. (1981), por meio da seguinte expressão:

Onde:

$$
\mathrm{ITGU}=\operatorname{Tgn}+0,36 \times \mathrm{Tpo}+41,5 \quad \text { eq. } 1
$$

Tpo $=$ Temperatura do ponto de orvalho $\left({ }^{\circ} \mathrm{C}\right)$

$\operatorname{Tgn}=$ Temperatura do globo negro $\left({ }^{\circ} \mathrm{C}\right)$

Os parâmetros fisiológicos mensurados foram: frequência respiratória (FR) determinada por meio de avaliação visual, observando-se os movimentos do flanco por 15 segundos, multiplicado por quatro para determinar os movimentos por minuto; frequência cardíaca (FC) ocorreu por meio de auscultação com o uso de estetoscópio, no lado esquerdo do animal, entre o $3 \circ$ e $5 \stackrel{\circ}{\circ}$ espaços intercostais, sendo a auscultação feita por 15 segundos e posteriormente determinada a frequência cardíaca por minuto; temperatura retal (TR) registrada por meio do uso de um termômetro clínico digital, inserido diretamente no reto do animal; temperatura de superfície corporal (TSC) medida na fronte, no dorso, na canela posterior e no úbere do animal, por meio de termômetro de infravermelho digital portátil. A média ponderada foi calculada atribuindose peso de $10 \%$ para a fronte, $70 \%$ para o dorso, $12 \%$ para a canela e $8 \%$ para o úbere de acordo com a metodologia descrita por PINHEIRO et al. (2005):

$\mathrm{TSC}=0,10 \times \mathrm{T}$. fronte $+0,7 \times \mathrm{T}$. dorso $+0,12 \times \mathrm{T}$. canela $+0,08 \times \mathrm{T}$. úbere eq. 2

Em que:

TSC $=$ temperatura de superfície corporal $\left({ }^{\circ} \mathrm{C}\right)$

$\mathrm{T}=$ temperatura $\left({ }^{\circ} \mathrm{C}\right)$.

As medições foram realizadas em função das estações climáticas (outono e primavera) e ordenha (antes do início e ao final da mesma).

Os pelos foram coletados uma vez a cada período do ano, por meio do uso de alicate do tipo "bico de pato", na região do costado, $20 \mathrm{~cm}$ abaixo da coluna vertebral, no centro do tronco. As amostras foram acondicionadas em envelopes de papel e identificadas, para contagem do número de pelos e comprimento. A espessura da capa de pelame foi determinada "in situ", no mesmo local de amostragem dos pelos, por meio do uso de um paquímetro digital da marca Insize.

A produção de leite foi obtida através da pesagem diária e anotação durante os dois períodos do experimento.

O delineamento utilizado para as variáveis fisiológicas, características do pelame e produção de leite foi o inteiramente casualizado em esquema fatorial $5 \times 2$ ( 5 grupos genéticos e 2 épocas do ano) com cinco repetições em cada tratamento. As variáveis foram submetidas à análise de variância e, quando significativas pelo teste $F$, tiveram as médias comparadas pelo teste de Tukey a $5 \%$ de probabilidade utilizando o software SISVAR (5.2) (FERREIRA 2008). O modelo estatístico utilizado foi o seguinte:

$$
Y i j=\mu+G_{-} i+P_{-} j+G_{-} i P_{-}(j)+\varepsilon \_i j
$$

Onde: Yijk é a variável dependente observada relativa a cada grupo animal “i”, no período "j"; $\mu$ é a média geral; Gi é o efeito dos grupos de animais "i”; Pj é o efeito dos períodos “j”; Gi Pj é a interação dos grupos e períodos; $\varepsilon i j$ é o erro aleatório. 


\section{RESULTADOS E DISCUSSÃO}

Nas duas épocas experimentais, os valores mínimos e médios de temperatura do ar estiveram dentro das condições consideradas adequadas, contudo, os valores máximos foram superiores aos recomendados, principalmente na primavera. Os valores médios da umidade relativa do ar ficaram na faixa desejável, já os extremos extrapolaram (Tabela 1). A faixa de termoneutralidade para animais mestiços está entre $7^{\circ} \mathrm{C}$ e 35 ${ }^{\circ} \mathrm{C}$ e da umidade relativa do ar entre $40 \%$ a $70 \%$ (SILVA 2000).

Tabela 1. Valores numéricos mínimos, médios e máximos das variáveis e índices climáticos verificados durante o outono e primavera.

Table 1. Minimum, mean and maximum numerical values of the variables and climatic indexes evaluated during autumn and spring.

\begin{tabular}{|c|c|c|c|c|c|c|c|c|c|}
\hline \multirow{2}{*}{$\begin{array}{l}\text { Variáveis e } \\
\text { Índices } \\
\text { Térmicos }\end{array}$} & \multicolumn{3}{|c|}{ Temperatura do $\operatorname{ar}\left({ }^{\circ} \mathrm{C}\right)$} & \multicolumn{3}{|c|}{ Umidade Relativa do ar (\%) } & \multicolumn{3}{|c|}{ ITGU } \\
\hline & $\overline{\text { Mín }}$ & Méd & Máx & Mín & Méd & Máx & Mín & Méd & Máx \\
\hline Outono & 7,3 & 22,3 & 40,1 & 15,0 & 52,5 & 91,7 & 54,1 & 79,0 & 95,4 \\
\hline Primavera & 15,9 & 27,8 & 44,8 & 21,6 & 71,2 & 100 & 65,2 & 79,3 & 96,0 \\
\hline
\end{tabular}

Nas duas épocas do ano estudadas os valores de ITGU estiveram acima do recomendado como confortável para bovinos nas horas mais quentes do dia (Gráfico 1). Durante a primavera foram verificados os maiores valores médios das variáveis e índices climáticos, contudo, a maior amplitude térmica ocorreu durante o outono.

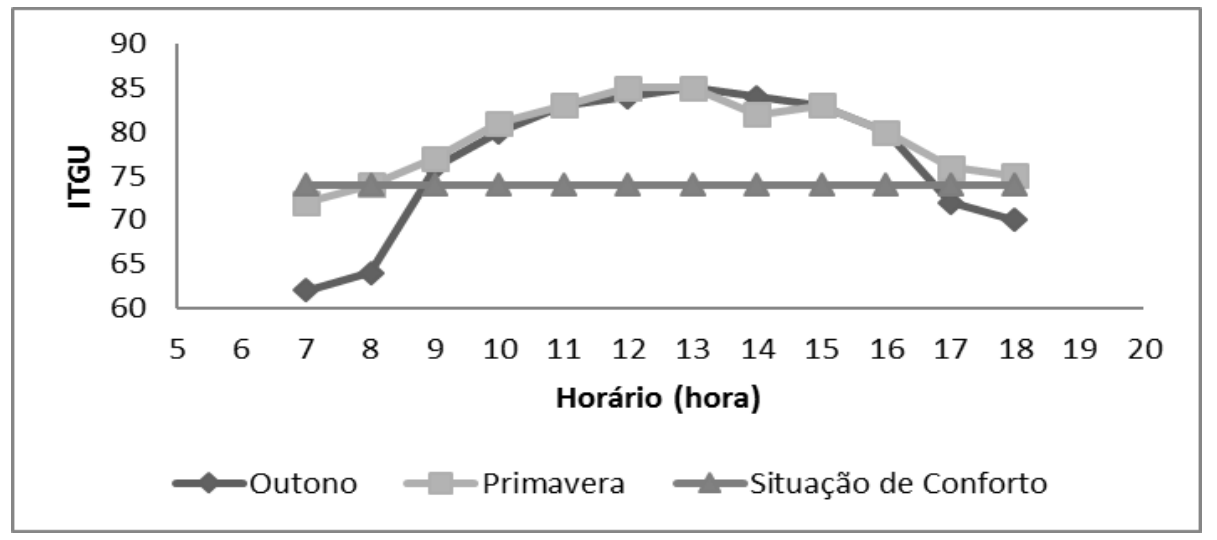

Gráfico 1. Valores médios de ITGU calculados para a estação do outono e primavera.

Graph 1. Mean Globe Temperature and Humidity Index (GTHI) values calculated for autumn and spring seasons.

Considerando os valores médios de ITGU obtidos nas duas estações do ano (igual ou superior a 79) (Tabela 1), o ambiente de criação pôde ser classificado como sinal de perigo, ou até mesmo de emergência quando atinge o seu pico mais alto (Gráfico 1). De acordo com BUFFINGTON et al. (1981), valores de ITGU até 74 definem conforto, de 74 a 78 é sinal de alerta, de 79 a 84 é sinal de perigo e acima de 84 é considerado sinal de emergência para bovinos.

Durante o período do outono, a frequência respiratória (FR) dos animais nos grupos genéticos estudados não diferiram entre si $(p<0,05)$ (Tabela 2). Na primavera, animais do grupo genético Holandês $x$ Nelore e Holandês $x$ Zebu apresentaram FR semelhantes, porém, apresentaram valores superiores aos animais dos demais grupos.

Ao comparar a FR dos animais de cinco grupos genéticos, verificou-se que os animais oriundos dos cruzamentos Holandês x Guzerá e Holandês x Nelore x Gir não diferiram nas duas épocas, ou seja, não necessitaram aumentar a frequência respiratória a fim de dissipar o excesso de calor corporal para manter a homeotermia. Os demais animais dos outros cruzamentos aumentaram a FR em torno de 3 a 6 mov. min $^{-1}$, na primavera para dissipar o calor.

Os animais apresentaram valores similares $(p<0,05)$ de frequência respiratória pela manhã nas duas estações do ano, entretanto, a FR foi superior no período da tarde e principalmente na primavera, devido às altas temperaturas observadas nesta estação, mas dentro da faixa considerada como ideal (Tabela 2). A frequência respiratória normal em bovinos adultos varia entre 24 e 36 movimentos respiratórios por minuto, 
mas pode apresentar valores mais amplos, entre 12 e 60 movimentos por minuto (GAUGHAN et al. 1999, FERREIRA et al. 2006).

Tabela 2. Efeito do ambiente climático sobre as respostas fisiológicas dos grupos genéticos e horários de ordenha

Table 2. Effect of the climatic environment on the physiological responses of genetic groups and milking schedules.

\begin{tabular}{|c|c|c|c|c|c|c|c|c|c|c|c|c|}
\hline \multirow{2}{*}{ Variáveis } & \multirow{2}{*}{ Estações } & \multicolumn{6}{|c|}{ Grupos genéticos } & \multicolumn{5}{|c|}{ Ordenha } \\
\hline & & $\mathrm{H} \times \mathrm{N}$ & $\mathrm{H} \times \mathrm{G}$ & $\mathrm{H} \times \mathrm{GU}$ & $\mathrm{H} \times \mathrm{Z}$ & $\mathrm{H} \times \mathrm{N} \times \mathrm{G}$ & Média & Manhã & Tarde & Média & Antes & Depois \\
\hline & Outono & $31,2 \mathrm{Ab}$ & $28,7 \mathrm{Ab}$ & $31,6 \mathrm{Aa}$ & $29,3 \mathrm{Ab}$ & $30,7 \mathrm{Aa}$ & 30,3 & $27,0 \mathrm{Aa}$ & $33,6 \mathrm{Ba}$ & 30,3 & 30,0 & 32,1 \\
\hline \multirow[t]{3}{*}{ FR } & Primavera & $34,3 \mathrm{Aa}$ & $32,0 \mathrm{Ba}$ & $31,0 \mathrm{Ba}$ & $35,7 \mathrm{Aa}$ & $32,5 \mathrm{Ba}$ & 33,1 & $28,1 \mathrm{Aa}$ & $38,3 \mathrm{Bb}$ & 33,2 & 33,1 & 34,2 \\
\hline & Média & 32,8 & 30,4 & 31,3 & 32,5 & 31,6 & & 27,5 & 36,0 & & & \\
\hline & Outono & $72,53 \mathrm{Aa}$ & $73,1 \mathrm{Aa}$ & $72,5 \mathrm{Ba}$ & $67,9 \mathrm{Ba}$ & $72,4 \mathrm{Ba}$ & 71,7 & $70,4 \mathrm{Aa}$ & $73,0 \mathrm{Aa}$ & 71,7 & 71,7 & 72,7 \\
\hline \multirow[t]{3}{*}{ FC } & Primavera & 76,3 Aa & $75,2 \mathrm{Aa}$ & $78,4 \mathrm{Aa}$ & $82,0 \mathrm{Aa}$ & $80,5 \mathrm{Aa}$ & 78,4 & $76,3 \mathrm{Ab}$ & $80,6 \mathrm{Bb}$ & 78,4 & 78,6 & 76,3 \\
\hline & Média & 74,5 & 74,2 & 75,5 & 75,0 & 76,4 & & 73,3 & 76,8 & & & \\
\hline & Outono & $30,8 \mathrm{Cb}$ & $31,2 \mathrm{Bb}$ & $31,2 \mathrm{Bb}$ & $31,2 \mathrm{Bb}$ & $31,5 \mathrm{Ab}$ & 31,2 & $29,4 \mathrm{Aa}$ & $31,2 \mathrm{Ba}$ & 30,3 & 31,0 & 32,8 \\
\hline \multirow[t]{3}{*}{$\mathrm{TSC}{ }^{\circ} \mathrm{C}$} & Primavera & $32,7 \mathrm{Ba}$ & $32,8 \mathrm{Ba}$ & $32,9 \mathrm{Aa}$ & $32,9 \mathrm{Aa}$ & $33,0 \mathrm{Aa}$ & 32,8 & $32, A b$ & $34,6 \mathrm{Bb}$ & 33,7 & 31,3 & 32,9 \\
\hline & Média & 31,7 & 32,0 & 32,0 & 32,1 & 32,2 & & 31,1 & 32,9 & & & \\
\hline & Outono & $38,1 \mathrm{Aa}$ & $38,3 \mathrm{Aa}$ & $38,1 \mathrm{Aa}$ & $38,0 \mathrm{Aa}$ & $38,2 \mathrm{Aa}$ & 38,2 & $37,8 \mathrm{Aa}$ & $38,1 \mathrm{Ba}$ & 38,17 & 37,9 & 38,4 \\
\hline \multirow[t]{2}{*}{$\mathrm{TR}^{\circ} \mathrm{C}$} & Primavera & $38,3 \mathrm{Aa}$ & $38,0 \mathrm{Aa}$ & $38,1 \mathrm{Aa}$ & $38,2 \mathrm{Aa}$ & $38,1 \mathrm{Aa}$ & 38,2 & $37,8 \mathrm{Aa}$ & $38,5 \mathrm{Ba}$ & 38,17 & 38,1 & 38,3 \\
\hline & Média & 38,2 & 38,2 & 38,1 & 38,1 & 38,2 & & 37,8 & 38,5 & & & \\
\hline
\end{tabular}

Médias seguidas pela mesma letra maiúscula nas linhas e minúscula nas colunas, não diferem entre si, pelo teste de Tukey a $5 \%$ de probabilidade. $\mathrm{FR}=$ Frequência respiratória em movimentos por minuto, $\mathrm{FC}=$ batimentos cardíacos por minuto, TSC = Temperatura de superfície corporal em ${ }^{\circ} \mathrm{C}, \mathrm{TR}=$ Temperatura retal em ${ }^{\circ} \mathrm{C}$. $\mathrm{H}=$ Holandês; $\mathrm{N}=$ Nelore; $\mathrm{G}=\mathrm{Gir}$; GU = Guzerá; $\mathrm{Z}=$ Zebu.

O aumento da frequência respiratória é o primeiro sinal visível dos animais quando submetidos ao estresse térmico. Entretanto, embora o ambiente tenha sido caracterizado como perigoso, todos os animais apresentaram valores de FR dentro da normalidade, o que se deve à introdução de raças zebuínas no cruzamento com animais de origem europeia, o que contribui para uma maior adaptação a ambientes adversos, já que estes são mais resistentes aos estressores ambientais (BÓ et al. 2003).

Valores de frequência respiratória superiores foram encontrados por FAÇANHA et al. (2016) em condições ambientais similares às do presente estudo. Os autores observaram médias de FR superiores para vacas Holandesas, de 37,10 movimentos/minuto no período seco do ano e 51,40 movimentos/minuto na época chuvosa. SILVA et al. (2010) observaram valores de frequência respiratória para vacas Jersey e Holandesa criadas a pasto e em região seca e quente variando de 46,3 a 79,5 movimentos/minuto. Esses resultados evidenciam a maior adaptabilidade dos animais mestiços ao ambiente de criação.

Os valores de frequência cardíaca dos animais por grupo genético estudado não diferiram entre si, tanto no outono quanto na primavera (Tabela 2). Contudo, animais dos grupos genéticos Holandês $x$ Guzerá, Holandês x Zebu e Holandês x Nelore x Gir apresentaram maiores valores na primavera, diferentemente dos animais dos grupos genéticos Holandês $x$ Nelore e Holandês $x$ Gir, que não apresentaram diferenças significativas em função das épocas, o que indica que esses cruzamentos conseguiriam manter a frequência cardíaca mesmo com o aumento de $5,5^{\circ} \mathrm{C}$ na temperatura do ar entre as estações (Tabela 1).

No outono, não houve variação da frequência cardíaca nos horários estudados, condição oposta ocorrida na primavera, onde, no período da tarde, os animais apresentaram valores superiores para este parâmetro. Neste período e no horário da tarde, as temperaturas atingiram valores próximos a $40^{\circ} \mathrm{C}$, o que contribui para o aumento do desconforto térmico dos animais e consequente alteração na sua fisiologia, a fim de manter a homeotermia.

Comparando as duas épocas do ano analisadas, pode-se verificar que os batimentos cardíacos alcançaram valores mais elevados na primavera, tanto pela manhã quanto no período da tarde, condição que pode ser explicada pelos valores crescentes e acumulativos de temperatura ao longo do dia.

Em trabalho durante a primavera com vacas Holandesas criadas em pasto, ÁVILA et al. (2013) encontraram valores de batimentos cardíacos no período da tarde, próximos aos obtidos no presente estudo, variando de 71,6 a 77,3 batimentos por minuto. BARBOSA et al. (2014) observaram valores de 
batimentos cardíacos inferiores para bovinos, com média de 60,3 batimentos por minuto para os animais mantidos à sombra e 67 batimentos por minuto para os animais mantidos no sol.

A frequência cardíaca dos animais não apresentou indicativos de estresse térmico, alcançando valores máximos próximos a 80 batimentos/minuto, ou seja, dentro da condição considerada como normal para a espécie bovina (PIRES et al. 2010), pois somente acima de 120 bat.min ${ }^{-1}$ os bovinos refletem carga excessiva de calor (HAHN \& MADER 1997).

Observa-se que no outono, animais do grupo genético Holandês x Nelore x Gir apresentaram temperatura de superfície corporal superior (TSC) aos animais dos demais grupos genéticos, e os animais do cruzamento Holandês $x$ Nelore apresentaram menores médias de temperatura superficial (Tabela 2). $\mathrm{Na}$ primavera, os animais dos grupos genéticos: Holandês $x$ Guzerá, Holandês $x$ Zebu e Holandês $x$ Nelore $x$ Gir apresentaram maiores médias de temperatura de superfície, destacando que, nessa época, temperaturas e umidade relativa foram mais elevadas, o que pode ter levado o aumento da temperatura de superfície em comparação com o outono.

Além disso, no período de coleta de dados da tarde, esses valores também foram superiores, o que é decorrente da maior incidência de radiação solar e das maiores temperaturas observadas na primavera, além do acúmulo de temperatura no decorrer do dia. Desse modo, como os animais ficavam expostos à radiação solar direta no pasto e na sala de espera para coleta de dados, houve influência no ganho de calor através do pelame.

Apesar da maioria dos animais de todos os cruzamentos apresentarem pelo e pele de cor escura, que facilita a absorção de calor, os valores de temperatura de superfície estiveram dentro do aceitável, indicando a adaptabilidade desses animais (Tabela 2). De acordo com MARTELLO et al. (2004), valores de temperatura superficial para bovinos entre 31,6 e $34,7 \stackrel{\circ}{ } \mathrm{C}$ não indicam sofrimento por estresse térmico nos animais e no presente estudo a média máxima foi de $34,6^{\circ} \mathrm{C}$, durante a primavera e no período da tarde.

Assim como neste estudo, FAÇANHA et al. (2016) também observaram variação nas condições climáticas entre diferentes épocas do ano (seca e chuvosa) e entre os horários do dia (manhã e tarde), refletindo em maior aquecimento corporal dos animais e alteração nos parâmetros fisiológicos.

SILVA et al. (2010) observaram valores superiores de temperatura de superfície corporal para vacas Jersey e Holandesas mantidas em região quente. A TSC dos animais variou de 34,0 a $41,2{ }^{\circ} \mathrm{C}$. DINIZ et al. (2017) não observaram diferenças na temperatura de superfície corporal em vacas mestiças de três diferentes cruzamentos (Holandês x Gir, Holandês x Nelore e Holandês x Nelore x Gir), no entanto, os animais apresentaram maior TSC no período da tarde $\left(37,7^{\circ} \mathrm{C}\right)$, horário no qual as médias de temperatura do ar, umidade relativa e ITGU foram superiores.

A temperatura retal dos animais nos cinco grupos genéticos não variou nas épocas estudadas (Tabela 2), entretanto, dentro de cada época, este parâmetro foi mais elevado no período da tarde. Resultados semelhantes foram observados por DINIZ et al. (2017) em trabalho com vacas mestiças F1 Holandês $x$ Zebu, onde não foram observadas variações para a temperatura retal entre os grupos genéticos avaliados, no entanto, os valores de TR foram superiores no período de coleta de dados da tarde $\left(38,8^{\circ} \mathrm{C}\right)$ em comparação com o período da manhã $\left(38,2^{\circ} \mathrm{C}\right)$.

DU PREEZ (2000) sugere valores de 38 a $39,3 \stackrel{\circ}{\circ} \mathrm{C}$ como temperatura retal normal para animais leiteiros, podendo ocorrer variações de acordo com a idade, sexo, nível nutricional, lactação e estágio reprodutivo. Assim, entende-se que o calor metabólico desprendido via frequência respiratória, frequência cardíaca e temperatura de superfície corporal foi suficiente para que os cruzamentos estudados atingissem a homeotermia.

Os valores de temperatura retal encontrados no presente estudo se assemelham aos obtidos por TOSETTO et al. (2014), que observaram médias variando de $37,73^{\circ} \mathrm{C}$ a $39,20^{\circ} \mathrm{C}$, para vacas Holandesas em semi-confinamento, valores considerados como normais para animais leiteiros.

Os valores encontrados para as variáveis fisiológicas (FR, FC, TSC e TR), antes e após as ordenhas, foram semelhantes $(p>0,05)$, e nas duas épocas os valores verificados estiveram dentro da condição aceitável para animais leiteiros.

A partir de observação e coleta de dados, verificou-se que todas as vacas F1 Holandês $x$ Zebu estudadas apresentaram epiderme pigmentada e o pelame mais espesso na época da primavera (Tabela 3), o que tende a dificultar a perda de calor corporal e contribuir para o aumento da temperatura de superfície corporal dos animais nesta época do ano.

As características morfológicas do pelame, como a sua espessura, influenciam no isolamento térmico proporcionado pela capa de pelos, sendo, em ambiente tropical, mais desejável que o animal apresente um menor isolamento térmico possível, desde que a sua epiderme seja pigmentada (SILVA 1999). 
No outono, animais pertencentes ao cruzamento Holandês x Nelore x Gir apresentaram a menor espessura de pelame, como forma de se preparar fisiologicamente para evitar a perda de calor interno para o meio em virtude das baixas temperaturas registradas no período.

A alteração no pelame e pelos ocorre em dois ciclos (mudas), alternando-se períodos de crescimento com períodos de quiescência. Uma muda acontece na primavera quando se forma o pelame de verão e a outra no outono que origina o pelame de inverno (SILVA 2000). Em virtude do período de realização do presente trabalho (início do outono e primavera), acredita-se que a espessura do pelame nos animais dos cruzamentos estudados tenha sido maior na primavera por estes estarem se ajustando fisiologicamente ao processo de transição de muda, ou seja, finalizando o período de inverno e iniciando a muda de verão.

Tabela 3. Efeito do ambiente climático sobre as características do pelame dos grupos genéticos. Table 3. Effect of the climatic environment on the characteristics of the hair coats of genetic groups.

\begin{tabular}{llllllll}
\hline Variáveis & \multirow{2}{*}{ Estações } & \multicolumn{7}{c}{ Grupos genéticos } \\
\cline { 3 - 8 } & & $\mathrm{H} \times \mathrm{N}$ & $\mathrm{H} \times \mathrm{G}$ & $\mathrm{H} \times \mathrm{GU}$ & $\mathrm{H} \times \mathrm{Z}$ & $\mathrm{H} \times \mathrm{N} \times \mathrm{G}$ & Média \\
\hline \multirow{2}{*}{$\begin{array}{l}\text { Número de } \\
\text { pelos }\end{array}$} & Outono & $190,5 \mathrm{Aa}$ & $97,1 \mathrm{Ab}$ & $66,2 \mathrm{Ab}$ & $131,6 \mathrm{Aa}$ & $81,2 \mathrm{Ab}$ & 133,3 \\
& Primavera & $186,2 \mathrm{Aa}$ & $145,5 \mathrm{Aa}$ & $135,2 \mathrm{Aa}$ & $178,7 \mathrm{Aa}$ & $153,4 \mathrm{Aa}$ & 159,8 \\
& Média & 188,3 & 121,3 & 100,7 & 205,1 & 117,32 & \\
\hline \multirow{2}{*}{$\begin{array}{l}\text { Comprimento } \\
\text { de pelos }\end{array}$} & Outono & $8,27 \mathrm{Ab}$ & $9,96 \mathrm{Aa}$ & $9,4 \mathrm{Aa}$ & $9,5 \mathrm{Ab}$ & $10,2 \mathrm{Ab}$ & $9,38 \mathrm{~b}$ \\
& Primavera & $12,1 \mathrm{Aa}$ & $11,3 \mathrm{Aa}$ & $12,6 \mathrm{Aa}$ & $12,7 \mathrm{Aa}$ & $12,6 \mathrm{Aa}$ & $12,3 \mathrm{a}$ \\
& Média & 10,22 & 10,6 & 11,0 & 11,1 & 11,4 & \\
\multirow{2}{*}{$\begin{array}{l}\text { Espessura do } \\
\text { pelame }\end{array}$} & Outono & $2,12 \mathrm{Bb}$ & $1,92 \mathrm{Bb}$ & $1,92 \mathrm{Bb}$ & $1,82 \mathrm{Bb}$ & $1,70 \mathrm{Ab}$ & 1,90 \\
& Primavera & $3,59 \mathrm{Aa}$ & $2,35 \mathrm{Aa}$ & $3,04 \mathrm{Aa}$ & $2,79 \mathrm{Aa}$ & $2,72 \mathrm{Aa}$ & 2,90
\end{tabular}

Médias seguidas pela mesma letra maiúscula nas linhas e minúscula nas colunas, não diferem entre si, pelo teste de Tukey a $5 \%$ de probabilidade. $\mathrm{H}=$ Holandês; $\mathrm{N}=$ Nelore; $\mathrm{G}=$ Gir; $\mathrm{GU}=$ Guzerá; $\mathrm{Z}=$ Zebu.

O mesmo entendimento é feito para o número pelos que foi maior na primavera nos animais dos cruzamentos $\mathrm{H} \times \mathrm{G}, \mathrm{H} \times \mathrm{Gu}$ e H $\times \mathrm{N} \times \mathrm{G}$, bem com o comprimento dos pelos verificados nos animais dos grupos: $\mathrm{H} \times \mathrm{N}, \mathrm{H} \times \mathrm{Z}$ e H $\times \mathrm{N} \times \mathrm{G}$. Na primavera, quando a muda preparativa de verão se inicia, a espessura do pelame, número e comprimento dos pelos diminuem para auxiliar no processo de trocas térmicas convectivas (SILVA 2000, PINHEIRO \& SILVA 2000).

Em trabalho avaliando as características morfológicas do pelame de vacas mestiças em região de clima quente, AIURA et al. (2014) não observaram diferenças significativas para a espessura do pelame dos animais entre as épocas do outono e primavera $(3,36 \mathrm{~mm}$ e $3,63 \mathrm{~mm}$, respectivamente). Ao estudar as características morfológicas do pelame de vacas Holandesas em região semiárida, MATA \& SILVA et al. (2013) não observaram variação para a espessura do pelame entre duas épocas do ano estudadas (julho/agosto e outubro/novembro), com média de 2,8 e $3,1 \mathrm{~mm}$ para a primeira e segunda época, respectivamente. Segundo os autores, dados de pesquisa sobre morfologia do pelame são escassos em regiões semiáridas, principalmente aquelas conduzidas com animais leiteiros, tanto os puros quanto para mestiços.

Apesar da diferença da espessura do pelame obtida no presente trabalho, entre as duas épocas do ano estudadas, os valores obtidos são considerados adequados para animais criados em regiões predominantemente quentes, como ocorre na maior parte do território brasileiro, facilitando a dissipação de calor e a manutenção da homeotermia.

Observa-se que a produção de leite variou entre os diferentes grupos genéticos nas duas épocas estudadas (Tabela 4). No outono, as vacas pertencentes aos grupos genéticos Holandês $x$ Gir e Holandês $x$ Nelore $x$ Gir apresentaram produção superior às demais. Na primavera as vacas dos grupos genéticos Holandês $x$ Gir, Holandês $x$ Zebu e Holandês $x$ Nelore $x$ Gir apresentaram produção superior às demais vacas dos outros grupos genéticos avaliados, mas não diferiram entre si. A variação de produção de leite entre vacas dos diferentes grupos avaliados pode ser atribuída a sua composição genética e não ao efeito ambiental.

A produção de leite pode ser entendida como o resultado final do processo de adaptabilidade dos bovinos leiteiros, pois, se o ambiente climático for capaz de influenciar nas respostas fisiológicas dos animais, os mesmos não atingem a homeotermia e consequentemente a produção é reduzida. 
Os valores verificados neste trabalho corroboram com os de GLÓRIA et al. (2006), onde a média de produção de leite das vacas F1 Holandês $x$ Zebu variou de 7,84 a 16,94 kg. Apesar do período de primavera (com média de temperatura de $27,8^{\circ} \mathrm{C}$, umidade relativa de 71,0 e ITGU de 79,3 ) ser caracterizado por apresentar variáveis climáticas mais elevadas que o outono e, possivelmente, expor os animais a uma condição de estresse térmico, a produção de leite foi superior nesta época.

Tabela 4. Efeito do ambiente climático sobre a produção de leite dos grupos genéticos.

Table 4. Effect of the climatic environment on milk production of genetic groups.

\begin{tabular}{llllllll}
\hline \multirow{2}{*}{ Variável } & Estações & \multicolumn{5}{c}{ Grupos genéticos } \\
\cline { 2 - 8 } & Outono & $\mathrm{H} \times \mathrm{N}$ & $\mathrm{H} \times \mathrm{G}$ & $\mathrm{H} \times \mathrm{GU}$ & $\mathrm{H} \times \mathrm{Z}$ & $\mathrm{H} \times \mathrm{N} \times \mathrm{G}$ & Média \\
\hline \multirow{2}{*}{$\begin{array}{l}\text { Produção } \\
\text { de leite }\end{array}$} & Primavera & $14,4 \mathrm{Cb}$ & $15,0 \mathrm{Aa}$ & $11,5 \mathrm{Cb}$ & $13,1 \mathrm{Bb}$ & $15,0 \mathrm{Ab}$ & 13,0 \\
& Média & 12,26 & $15,2 \mathrm{Aa}$ & $13,5 \mathrm{Ba}$ & $15,6 \mathrm{Aa}$ & $16,4 \mathrm{Aa}$ & 15,0 \\
& & 15,09 & 12,48 & 14,38 & 15,69 & \\
\hline
\end{tabular}

Médias seguidas pela mesma letra maiúscula nas linhas e minúscula nas colunas, não diferem entre si, pelo teste de Tukey a $5 \%$ de probabilidade. $\mathrm{H}=$ Holandês; $\mathrm{N}=$ Nelore; $\mathrm{G}=$ Gir; $\mathrm{GU}=$ Guzerá; $\mathrm{Z}=$ Zebu.

Ao estudar a influência da temperatura ambiente no verão sobre a produção de leite de vacas Holandesas criadas a pasto, NASCIMENTO et al. (2017) observaram um decréscimo de $20 \%$ na produção diária de leite no período da tarde em relação ao período da manhã, o que foi correlacionado às altas temperaturas do ar nesse horário do dia e à grande variação de temperatura dentro da sala de ordenha entre os dois períodos avaliados (cerca de $10^{\circ} \mathrm{C}$ ), o que impactou negativamente na produção das vacas da raça Holandesa.

Dessa forma, a criação de vacas mestiças F1 Holandês x Zebu em países de clima tropical onde há o predomínio do sistema extensivo com exposição direta de radiação solar, bem como em estações climáticas onde são registrados altos valores de ITGU é totalmente viável. De acordo com os dados apresentados neste trabalho, as alterações fisiológicas e os ajustes do pelo e pelame refletem os ajustes naturais que os animais realizam em busca da homeotermia, sem afetar a condição de conforto dos grupos avaliados. Tal fato é confirmado pela produção de leite que mantêm-se dentro dos valores esperados para mestiços e que se diferencia somente em função da composição genética.

O conhecimento a respeito da adaptabilidade das vacas F1 Holandês $x$ Zebu ao clima tropical associado ao manejo nutricional ajustado às exigências térmicas regionais é imperativo aos produtores para que providências sejam tomadas no sentido de reduzirem os impactos negativos e inevitáveis, preconizados com o aquecimento global.

\section{CONCLUSÃO}

As variáveis ambientais nas duas estações do ano não promoveram grandes alterações nas respostas fisiológicas e produtivas dos animais, indicando adaptação destes às condições climáticas do ambiente de criação. No entanto, houve diferenças entre épocas para a maioria dos parâmetros fisiológicos estudados, sendo estes mais elevados na primavera e no horário da tarde.

\section{AGRADECIMENTOS}

À CAPES, FAPEMIG, CNPq e EPAMIG.

\section{REFERÊNCIAS}

AIURA ALO et al. 2014. Características morfológicas do pelame de vacas mestiças. Revista Brasileira de Saúde e Produção Animal 15: 866-871.

ÁVILA AS et al. 2013. Avaliação e correlação de parâmetros fisiológicos e índices bioclimáticos de vacas Holandês em diferentes estações. Revista Eletrônica em Gestão, Educação e Tecnologia Ambiental 14: 2878-2884.

AZEVEDO $\mathrm{M}$ et al. 2005. Estimativa de níveis críticos superiores do índice de temperatura e umidade para vacas leiteiras 1/2, 3/4, 7/8 Holandês-Zebu em lactação. Revista Brasileira de Zootecnia 34: 2000-2008.

BAÊTA F \& SOUZA FC. 2010. Ambiência em edificações rurais: conforto animal. 2.ed. Viçosa: UFV. 247p.

BARBOSA BRP et al. 2014. Tolerância ao calor em bovinos da raça Nelore Branco, Nelore Vermelho e Pantaneira. Revista Brasileira de Saúde e Produção Animal 15: 854-865.

BÓ GA et al. 2003. Pattern and manipulation of follicular development in Bos indicus cattle. Animal Reprodution Science 78: 307-326.

BUFFINGTON DE et al. 1981. Black globe-humidity index (BGHI) as comfort equation for dairy cows. Transactions of 
the ASAE 24: 711-714.

CARVALHO LA et al. 2016. Importância econômica. Embrapa Gado de Leite.

DINIZ TA et al. 2017. Vacas F1 Holandês x Zebu no terço final de gestação apresentam adaptação fisiológica quando criadas no ambiente semiárido. Revista de Ciências Agroveterinárias 16: 70-75.

DU PREEZ JH. 2000. Parameters for the determination and evaluation of heat stress in dairy cattle in South Africa. Onderstepoort Journal of Veterinary Research 67: 263-271.

FAÇANHA DAE et al. 2016. Produção de leite e respostas fisiológicas de vacas da raça Holandesa em ambiente quente. Revista Acta Veterinaria Brasilica 10: 208-215.

FERREIRA DF. 2008. Programa Sisvar versão 5.1. Programa de análises estatísticas. Lavras: DEX/UFLA.

FERREIRA $F$ et al. 2006. Parâmetros fisiológicos de bovinos cruzados submetidos ao estresse calórico. Arquivo Brasileiro de Medicina Veterinária e Zootecnia 58: 732-738.

GAUGHAN JB et al. 1999. Heat tolerance of Boran and Tuli crossbred steers. Journal Animal Science 77: 2398-2405.

GLÓRIA JR et al. 2006. Efeito da composição genética e de fatores de meio sobre a produção de leite, a duração da lactação e a produção de leite por dia de intervalo de partos de vacas mestiças Holandês-Gir. Arquivo Brasileiro de Medicina Veterinária e Zootecnia 58: 1139-1148.

HAHN GL \& MADER TL. 1997. Heat waves in relation on thermoregulation, feeding behavior, and mortality of feedlot cattle. In: Proceedings of 5th International Livestock Environment Symposium. Minneapolis: ASAE. p. 563-571.

MARTELLO LS et al. 2004. Respostas fisiológicas e produtivas de vacas holandesas em lactação submetidas a diferentes ambientes. Revista Brasileira de Zootecnia 33: 181-191.

MATA \& SILVA BC et al. 2013. Características morfológicas do pelame de vacas holandesas puras por cruza na região semiárida de Minas Gerais. Arquivo Brasileiro de Medicina Veterinária e Zootecnia 65: 1767-1772.

NASCIMENTO ST et al. 2017. Influência da temperatura ambiente no verão na produção de leite de vacas Holandesas. Revista Pubvet 11: 217-223.

PINHEIRO MG \& SILVA RG. 2000. Estação do ano e características do pelame de vacas da raça Holandesa. Boletim Indústria Animal 57: 99-103.

PINHEIRO MG et al. 2005. Efeito do ambiente pré-ordenha (sala de espera) sobre a temperatura da pele, a temperatura retal e a produção de leite de bovinos da raça Jersey. Revista Portuguesa de Zootecnia 12: 37-43.

PIRES MFA et al. 2010. Adaptação de animais mestiços em ambiente tropical. Informe Agropecuário 31: 30-38.

RUAS JRM et al. 2010. Sistema de Produção de Leite com vacas F1 Holandês x Zebu. Informe Agropecuário 31: $63-71$.

SEJIAN V et al. 2010. Adaptive capability as indicated by endocrine and biochemical responses of Malpura ewes subjected to combined stress (thermal and nutritional) in a semi-arid tropical environment. International Journal of Biometeorology 54: 653-661.

SILVA RG. 1999. Estimativa do balanço térmico por radiação em vacas Holandesas expostas ao sol e à sombra em ambiente tropical. Revista Brasileira de Zootecnia 28: 1403-1411.

SILVA RG. 2000. Introdução à bioclimatologia animal. São Paulo: Editora Nobel. 286p.

SILVA RG et al. 2010. Índice de estresse térmico para vacas leiteiras em regiões equatoriais secas. Revista Científica de Produção Animal 12: 125-128.

TOSETTO MR et al. 2014. Influência do macroclima e do microclima sobre conforto térmico de vacas leiteiras. Journal Behavioral Biometeorology 2: 6-10.

VASCONCELLOS B et al. 2003. Efeitos genéticos e ambientais sobre a produção de leite, o intervalo de partos e a duração da lactação em um rebanho leiteiro com animais mestiços, no Brasil. Revista Universidade Rural: Série Ciências da Vida 23: 39-45. 